\title{
Behavior of Two Foundry Cobalt-Based Alloys Exposed to a Hot Complex Gaseous Mixture Simulating the Atmosphere in a Waste- to-Energy Boiler. Part 2: Case of the Alloy Immersed in Synthetic Ashes
}

\author{
Lionel Aranda ${ }^{1}$, Thierry Schweitzer ${ }^{1}$, Patrice Berthod ${ }^{1, *}$, Christophe Rapin ${ }^{1}$, \\ Didier Souchon ${ }^{2}$, Farès Maad ${ }^{2}$ and Jean-Michel Brossard ${ }^{2}$
}

\author{
${ }^{1}$ Institut Jean Lamour (UMR 7198), University of Lorraine, Campus ARTEM, 2 allée André Guinier 54000 \\ Nancy, France \\ ${ }^{2}$ Veolia Environnement Recherche et Innovation, Zone Portuaire, 291 Avenue Dreyfous Ducas, 78520 Limay, \\ France
}

\begin{abstract}
Currently cobalt-based alloys are seemingly not really envisaged for constituting waste-to-energy boilers, although that the WtE working conditions are similar to those encountered in some applications in which Co-based superalloys are successfully used. To test the behavior of the cast chromium-rich cobalt-based alloys' family, two model alloys belonging to the later one were cast and samples were exposed during more than ten days to a hot complex gaseous mixture and to synthetic ashes. After test the samples were characterized by X-ray diffraction and SEM observations. The results of the characterization of the first sample, the one exposed to the hot complex gaseous atmosphere, were presented in the first part of this work. This second part concerns the post-mortem analysis of the second sample, the one immersed in ashes. It appears first that this one was not protected by any external oxide scale. Instead, a mixture of oxides and chlorides formed and reaction between these corrosion products with ashes obviously led to an intermediate liquid phase. Internal oxidation/chloridation of the chromium carbides network obviously occurred over a $500 \mu \mathrm{m}$-depth from the surface happened. The responsibility of an active oxidation mechanism analogous to what was earlier observed on steels is envisaged.
\end{abstract}

Keywords: Cobalt-chromium alloys, Synthetic ashes, Hot corrosion, Active oxidation phenomenon.

\section{INTRODUCTION}

The fireside heat-recovery from municipal refuse burning is of great interest since many years ago [1]. Unfortunately the degradation of metallic materials used in incinerators by the products resulting from this combustion is also an old problem [2]. Some boilers tubes may be protected by deposits involving nickelbased alloys deriving from coatings for superalloys [3] or from superalloys themselves [4]. Different alloys or coatings solutions are currently tested in environments simulating the incinerator's ones [5-7] but some tests may be carried out in in situ real conditions [8]. Steels and nickel-based alloys are among the alloys which are the most used for boilers. Despite their refractoriness which is at least as high as the ones of steels and nickel alloys [9], and their well-known resistance against high temperature corrosion [10], the family of cobalt-based alloys and superalloys seems to be ignored at this time for this application. One must just cite some works which deal with this subject $[11,12]$.

*Address correspondence to this author at the Institut Jean Lamour (UMR 7198), University of Lorraine, Campus ARTEM, 2 allée André Guinier 54000 Nancy, France ; Tel: +33-372 7427 29;

E-mail: patrice.berthod@univ-lorraine.fr
The subject of this work divided in two parts is to evaluate the behaviour of two simplified cobalt-based alloys. Many cobalt-based superalloys are strengthened by carbides. The carbides strengthening the alloy already studied in contact with complex gaseous stream in the first part of this work [13] are chromium carbides. The second alloy, which will be here exposed to synthetic ashes in the same atmosphere as the first one, contain another type of carbides important for cobalt alloys: chromium carbides. After a long time of exposure (more than ten days) its degradation is characterized and the results discussed in this work.

\section{MATERIALS AND METHODS}

The sample which will be immersed in synthetic ashes comes from an ingot especially elaborated by foundry in the frame of an earlier study. The alloy, called "CRC", contains nickel (10wt.\%), chromium (30wt.\%), carbon (0.5wt.\%) and cobalt (bal.). The roles of $\mathrm{Ni}, \mathrm{Cr}$ and $\mathrm{C}$ are respectively: stabilizing the Face Centred Cubic crystalline network of the matrix, allowing the alloy to be possibly resistant against hot oxidation and corrosion, and promoting the formation of carbides for improving the mechanical properties at 
high temperature. The wished microstructure was successfully obtained: a dendritic matrix of cobalt containing all nickel and the main parts of chromium and carbon, and interdendritic chromium carbides.

The "CRC" sample was tested in the same apparatus as the "TAC" alloy of the first part of this work [13]. One can shortly remind that this apparatus was designed to reproduced the conditions of working of WtE boilers: production of a hot mixture gas containing 1100 ppm of $\mathrm{HCl}, 18 \%$.vol $\mathrm{H}_{2} \mathrm{O}, 8 \%$.vol $\mathrm{O}_{2}$ and $5 \%$.vol $\mathrm{CO}_{2}$ with flying ashes. Unlike the "TAC" sample, the "CRC" sample was immersed in a crucible which contains $\mathrm{NaCl}$ playing the role of synthetic ashes. In these conditions it was exposed to $550^{\circ} \mathrm{C}$ for 260 hours.
After test the "CRC" sample was first subjected to X-ray diffraction (XRD), before being embedded in a cold resin mixture. After cutting, grinding was carried out, with successive SiC papers from 240 to 2400-grit. During this operation Kerdane was used as lubricant at the expense of water, to avoid any deterioration of the corrosion products. Final polishing was thereafter done using a textile disk enriched with $1 \mu \mathrm{m}$ diamond particles, under ethanol as lubricant.

Examinations involved a JEOL JSM6010LA Scanning Electrons Microscope (SEM) for imaging, essentially in the Back Scattered Electrons (BSE) mode. Chemical analysis was carried out using the Energy Dispersive Spectrometry (EDS) device attached to the SEM.

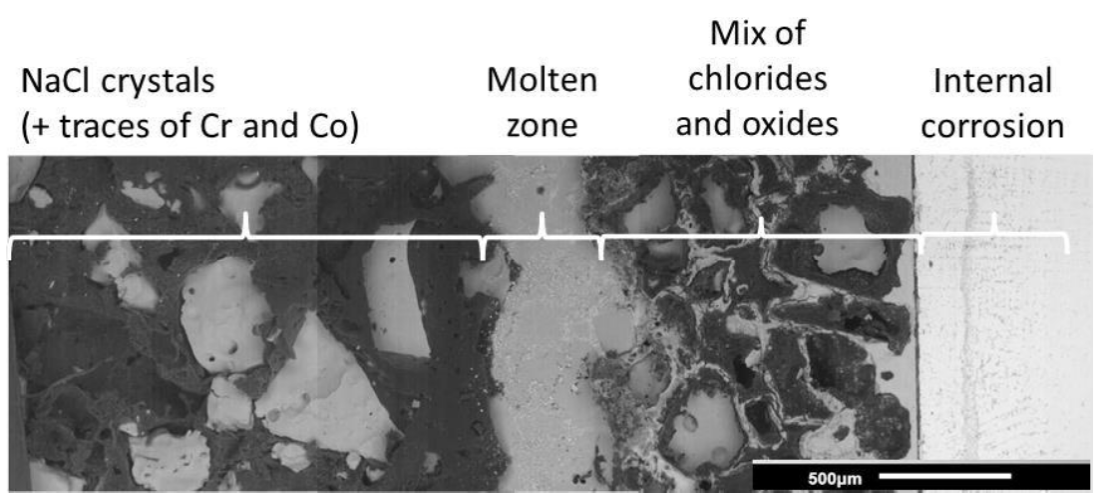

Figure 1: SEM observation of the different layers composing the corrosion products formed on the immersed "CRC" sample, from the outer part (left) to the inner part (right).

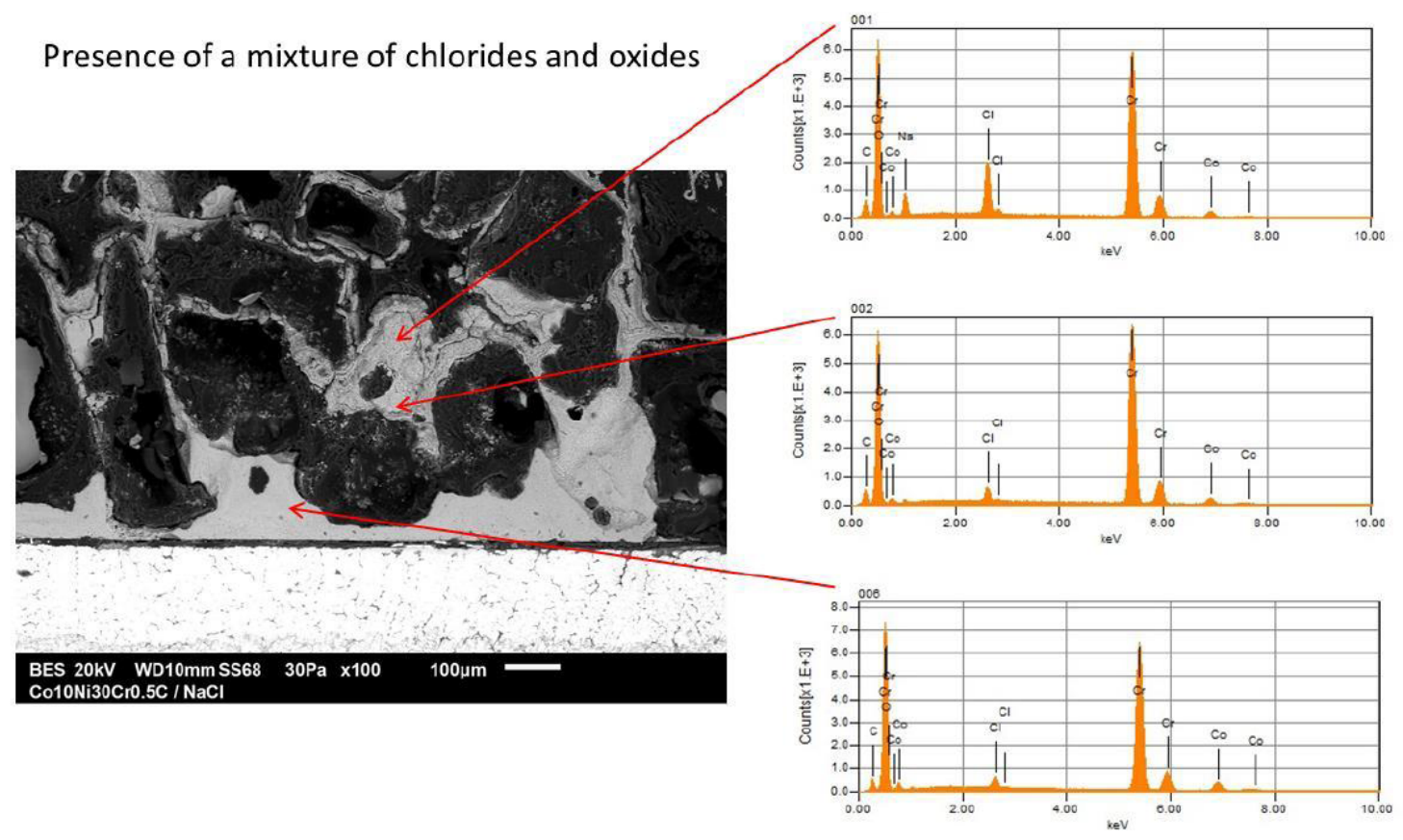

Figure 2: SEM/BSE imaging and EDS spot analysis of the corrosion products present close to the interface with the "CRC" alloy. 

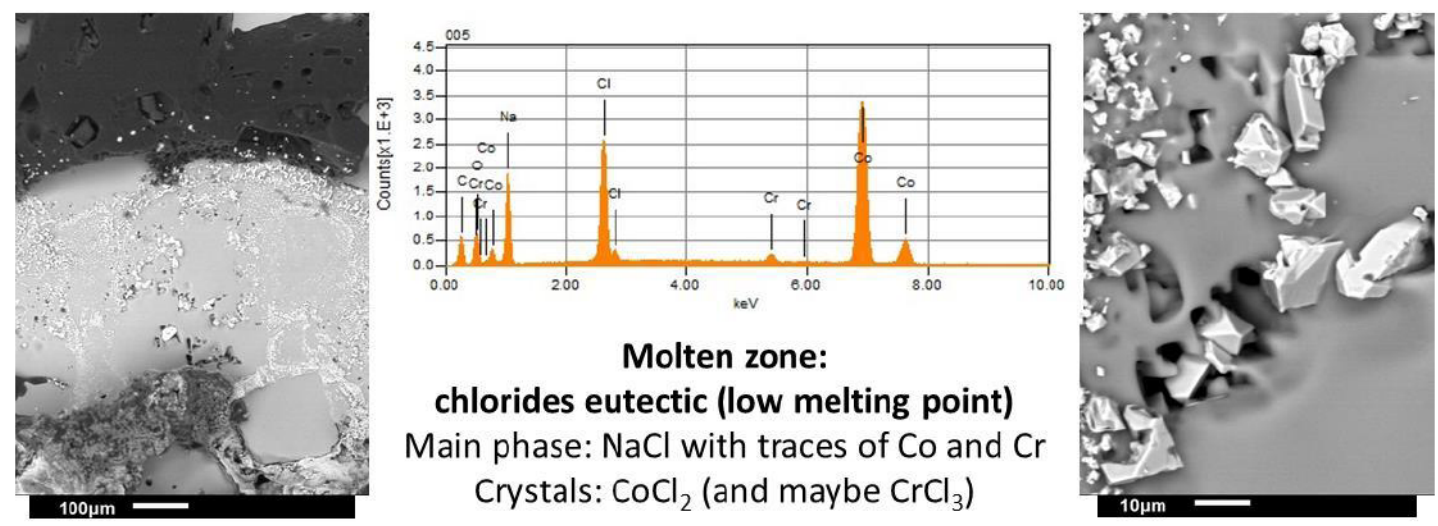

Figure 3: SEM/BSE observation of the molten zone at higher magnifications (immersed "CRC" sample).

\section{RESULTS}

The "CRC" alloy severely corroded. Figure 1 illustrates the different layers formed over the alloy, as seen with the SEM in BSE mode. Crystals of sodium chloride crystals, containing additionally a little of chromium and cobalt, are present in the outermost part of the corrosion products. The inner part is a mixture of chlorides and nitrides (Figure 2). Between the two a curious zone exists. This one seems resulting from a fusion of the corrosion products locally present. It contains mainly $\mathrm{NaCl}$, some traces of $\mathrm{Co}$ and $\mathrm{Cr}$, and also seemingly $\mathrm{CoCl}_{2}$ and even $\mathrm{CrCl}_{3}$ crystals as identified by local EDS measurements (Figure 3). One can guess that the substance present here results from the formation of chlorides eutectic with low melting point.

In its subsurface the "CRC" alloy particularly suffered during this long high temperature immersion stay in the synthetic ashes, notably because no oxide scale such as chromia developed and protected it. Internal corrosion took place over a depth of more than $500 \mu \mathrm{m}$, by the oxidation and chloridation of the interdendritic network of eutectic chromium carbides (Figure 4).

\section{DISCUSSION}

As already noted with the "TAC" alloy which was only exposed to the gaseous mixtures upstream in the first part of this work [13], the "CRC" alloy was severely degraded, although that the test temperature was not particularly high by comparison with other processes in which such alloy can be used.

As previously noticed for the "TAC" alloy, the "CRC" alloy, after its long in these synthetic ashes composed of $\mathrm{NaCl}$, it underwent itself an outer attack and an inner one. The corrosion products formed on surface are composed of an inner layer of mixture of oxides and chlorides. Oxides resulted from oxidation by the aggressive gases composing the complex atmosphere, certainly by oxygen and maybe also by water vapor. Chlorides may result from the reaction of the solid state reaction of the surface of the sample with the solid parts of sodium chloride.

Another possible explanation of the appearance of these cobalt chlorides is the presence of gaseous $\mathrm{Cl}_{2}$ formed from $\mathrm{HCl}(\mathrm{g})$ present in the generated complex gaseous atmosphere, according to the Deacon equilibrium, allowing an active oxidation phenomena similar to the one described by Grabke [14] in the case of steels (summarized in Figure 5 ). This second hypothesis, which allows the presence of $\mathrm{Cl}_{2}$, may explain the chloridation of the chromium carbides even very deep in the alloy. The formed $\mathrm{CoCl}_{2}$ in contact with $\mathrm{NaCl}$ possibly led to the formation of a liquid phase, favored by the existence of a low temperature melting eutectic $39 \mathrm{~mol} . \% \mathrm{CoCl}_{2}-61 \mathrm{~mol} . \% \mathrm{NaCl}$ (eutectic temperature near $350^{\circ} \mathrm{C}$, Figure 6).

One must notice that the "TAC" alloy too was possibly exposed to chloridation since $\mathrm{HCl}$ and $\mathrm{O}_{2}$ gases were also present in the vicinity of the surface of this sample [13]. The reaction of cobalt and nickel with $\mathrm{Cl}_{2}$ resulting from the Deacon equilibrium may generate $\mathrm{CoCl}_{2}$ solid with possible a low partial pressure of $\mathrm{CoCl}_{2}$ gas. Furthermore $\mathrm{NaCl}$ coming from the ashes introduced upstream may react with such other chlorides. So the degradation of the "TAC" alloy was expected to be almost as severe as the "CRC" alloy one. This was obviously not the case, even if the corrosion products formed on the "TAC" alloy were noticeable [13]. Seemingly the external oxide scale, even not ideal (composed of $(\mathrm{Co}, \mathrm{Ni}) \mathrm{O}$ and spinel $\mathrm{CoCr}_{2} \mathrm{O}_{4}$, and not $\mathrm{Cr}_{2} \mathrm{O}_{3}$ ), avoided this scenario. Furthermore tantalum carbides are perhaps much more 


\section{Internal corrosion; oxidation/chloridation of the chromium carbides network over more than $500 \mu \mathrm{m}$ in depth}
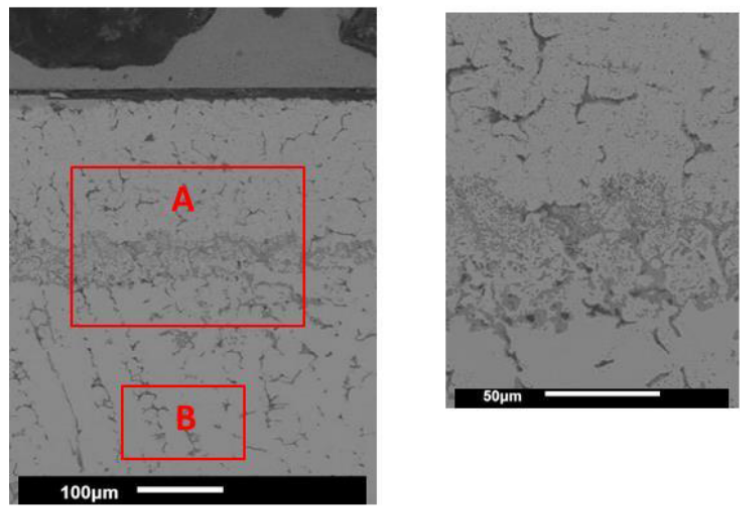

A
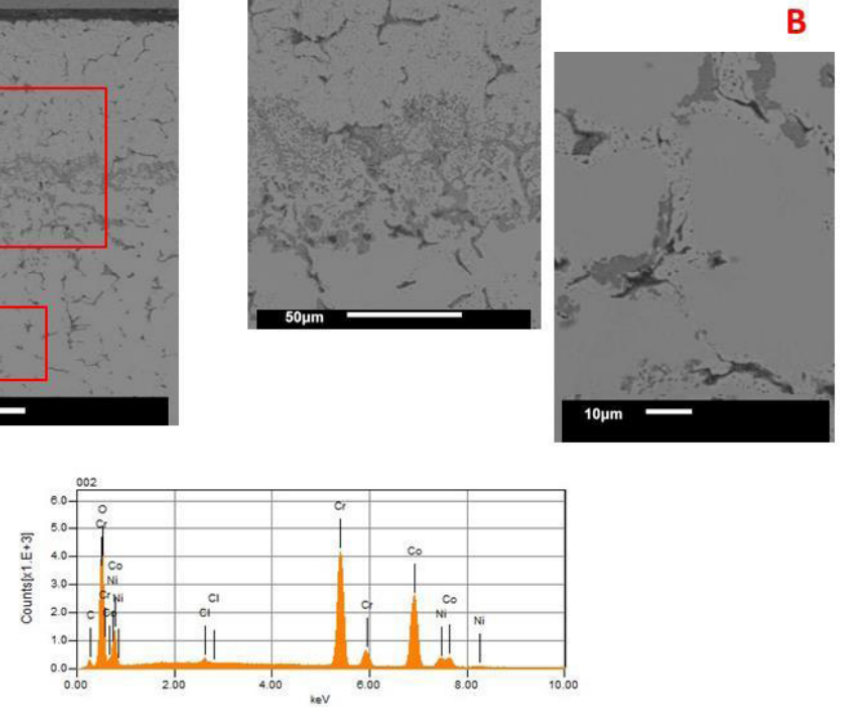

Figure 4: SEM/BSE visualization of the internal corrosion affecting the subsurface of the "CRC" alloy; oxidation/chloridation of the interdendritic network of chromium carbides.

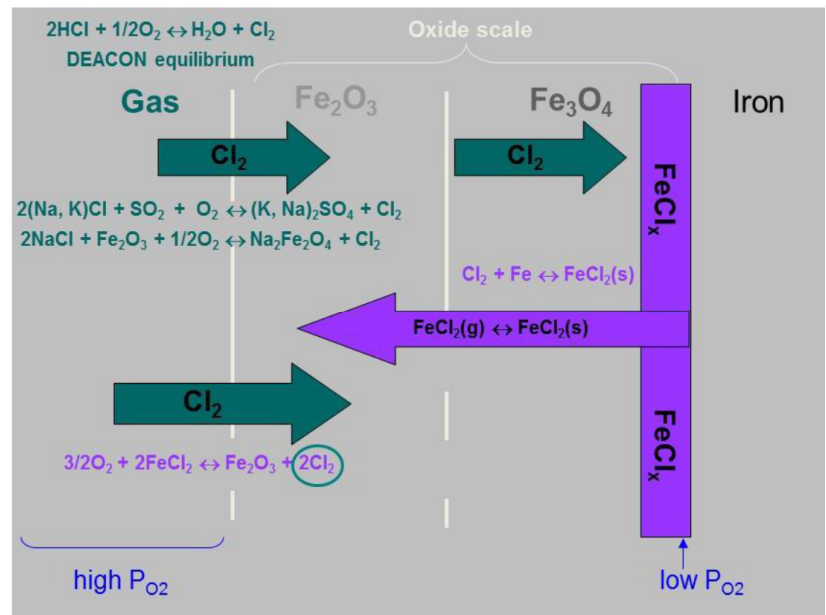

Figure 5: Scheme of the active oxidation process in case of a steel exposed to hot $\left\{\mathrm{HCl} / \mathrm{Cl}_{2}\right\}$-containing atmosphere, according to Grabke [14].

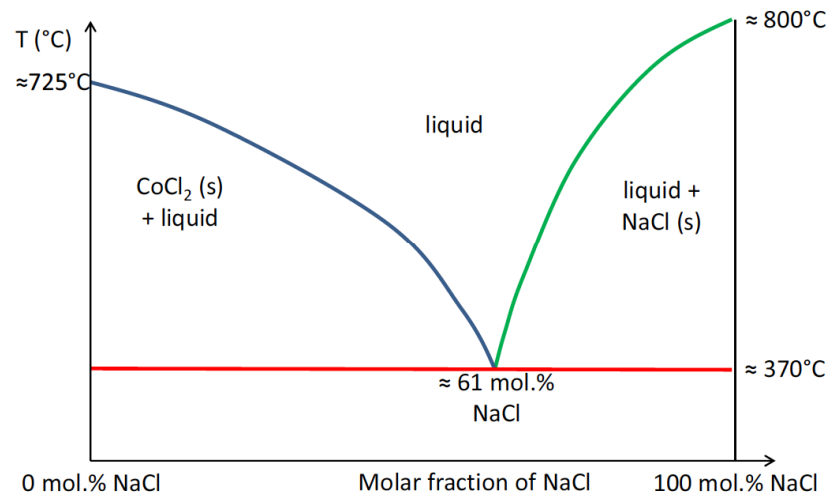

Figure 6: Phase diagram of the binary system $\mathrm{NaCl}-\mathrm{CoCl}_{2}$. 
resistant against chloridation than chromium carbides: the phenomenon which affected the chromium carbides of the "CRC" alloy over a particularly deep zone did not take place for the TaC carbides.

\section{CONCLUSIONS}

In this second part of the study the second selected cobalt-based alloy did not well behave in the complex gaseous atmosphere with simultaneous contact with synthetic ashes. Although it is among the most resistant cobalt-based alloys in oxidation at much higher temperature than here, thanks to the presence of $10 \mathrm{wt} . \% \mathrm{Ni}$ and $30 \mathrm{wt} . \% \mathrm{Cr}$ and to the chromium carbides network allowing $\mathrm{Cr}$ availability in the interdendritic spaces and fast $\mathrm{Cr}$ diffusion towards the oxidation front, the "CRC" alloy suffered severe degradation during these more than ten days at only $550^{\circ} \mathrm{C}$. An active oxidation phenomenon is probably to point out and to more precisely describe later by taking example of the model of Grabke for iron-based alloys. Clearly, the presence of $\mathrm{HCl}$ and of $\mathrm{NaCl}$ led to a particularly important role of the $\mathrm{Cl}$ element, with notably the appearance of a molten mixture of $\mathrm{NaCl}$ and $\mathrm{CoCl}_{2}$. This melt is possibly responsible to the absence of development of the protective chromia scale which usually prevents fast oxidation and corrosion for this alloy. Furthermore it is also possible that the presence of a rather well developed interdendritic carbides network is more disadvantageous than advantageous since it seems deep favoring chloride formation in the alloy. TaC carbides are maybe better in this way since carbides' chloridation was not detected in the "TAC" alloy [13].

To summarize, it seems at the present stage that cobalt-based alloys are less interesting than nickel alloys. This is probably due to their microstructure involving an interdendritic carbide network. Outlooks may be the test, in the same conditions as here, carbides-free solid solution strengthened cobalt-based alloys to state about the role of carbides and on their responsibility in the bad behaviors observed in this study.

\section{ACKNOWLEDGMENTS}

This work was carried out by several members of the french Groupe de Recherche GDR CNRS 3583 "EVACOHT" (Effet de la Vapeur d'eau en Atmosphères complexes sur la Corrosion et l'Oxydation à Haute Température). The authors wish thanking the Centre National de la Recherche Scientifique (CNRS) for the favorable conditions brought to this work.

\section{REFERENCE}

[1] Vaughan DA, Miller PD. United States National Technical Information Service, PB Report N²21851/9 (1973).

[2] Clark MW. Proceedings of the Process Industrial Corrosion Conference, 1975; 329.

[3] Kalsi SS, Sidhu TS, Singh H, Karthikeyan J. Engineering Failure Analysis, 2014; 46: 238. https://doi.org/10.1016/j.engfailanal.2014.09.001

[4] Solecka M, Kusinski J, Kopia A, Rozmus-Gornikowska M, Radziszewska A. Acta Physica Polinica A, 2016; 130(4): 1045. https://doi.org/10.12693/APhysPolA.130.1045

[5] Mudgal D, Singh S, Prakash S. Journal pf Materials Engineering and Performance, 2014; 23(1): 238.

[6] Montgomery M, Hansson AN, Jensen SA, Vilhelmsen $T$, Nielsen NH. Materials and Corrosion 2013; 64(1): 14. https://doi.org/10.1002/maco.201006019

[7] Galetz MC, Bauer JT, Schütze M, Noguchi M, Takatoh C, Cho H. Materials and Corrosion 2014; 65(8): 778. https://doi.org/10.1002/maco.201206787

[8] Singh H, Sidhu TS. Oxidation of Metals 2013; 80(5-6): 651. https://doi.org/10.1007/s11085-013-9414-y

[9] Bradley: "Superalloys: A Technical Guide", ASM International, Metals Park (1988).

[10] Kofstad P. "High Temperature Corrosion", Elsevier Applied Science, Amsterdam (1988).

[11] Jegede A, Vasantasree V, Hocking MG. Journal of Materials Science Letters 1995; 14: 858 https://doi.org/10.1007/BF00639306

[12] Jegede A, Vasantasree $V$, Hocking MG. Journal of Materials Science Letters 1995; 14(15): 1089. https://doi.org/10.1007/BF00258173

[13] Aranda L, Schweitzer T, Berthod P, Rapin C, Souchon D, Maad F, Brossard JM. Journal of Materials Science and Technology Research 2018; 5: 1-5.

[14] Grabke HJ. Incinerating Municipal and Industrial Waste, Bryers R.W. Hemisphere Publ. Corp, 1991; 161.

\section{DOI: http://dx.doi.org/10.31875/2410-4701.2018.05.2}

(c) 2018 Aranda et al.; Zeal Press.

This is an open access article licensed under the terms of the Creative Commons Attribution Non-Commercial License (http://creativecommons.org/licenses/by-nc/3.0/), which permits unrestricted, non-commercial use, distribution and reproduction in any medium, provided the work is properly cited. 